\title{
A Homeopathic Perspective on Obstetrics and Gynecology Research
}

\author{
Mohammad-Hossein Biglu' ${ }^{1}$, KhaterehYousefi $\operatorname{Rad}^{2}$, Sahar Biglu ${ }^{3}$, Hamed Serati-Nouri ${ }^{*}$
}

\begin{abstract}
Objectives: Homeopathy is an alternative medicine which reacts based on the principal as 'likes cures likes'. Small amount and much diluted medicine of original substance that produces signs and symptoms in healthy individuals can treat disease with similar signs and symptoms. Many studies have confirmed the positive effects of homeopathic medicines. Homeopathy is a perfect complement to the science of midwifery. Many women's health problems are easily treated with homeopathic medicines. The objective of current study is to visualize and analyze the scientific activities by leading countries in the field of Homeopathy and Midwifery.

Materials and Methods: All papers entitled Homeopathy in the database of Web of Science were extracted and went under contain analysis. Databases of Science Citation Index Expanded SCI-E) and Social Science Citation Index SSCI) from Web of Science were used to obtain all row data.

Results: Retrieving of data led a total number of 1830 papers entitled homeopathy. The contain analysis of extracted papers showed that only $2 \%$ of them was in the subject area of Obstetrics \& Gynecology. England was the leading country regarding to producing and publishing papers in the field of homeopathy followed by USA and Germany respectively.

Conclusion: Regarding to the effective role of homeopathy on Obstetrics \& Gynecology, the portion of performed research activities in the subject area of homeopathy seems to be very redundant and small.

Keywords: Scientometrics, Bibliometrics, Homeopathy, Obstetrics, Gynecology
\end{abstract}

\section{Introduction}

Homeopathy is an alternative medicine which was developed by German physician and chemist Samuel Hahnemann. It is based on the principal as 'likes cures likes. Small amount and very diluted medicine of original substance that produces signs and symptoms in healthy individuals can treat the diseases with the same signs and symptoms (1). Remedies mainly are derived from animal, mineral or plant substances, and experience a pharmaceutical process known as "potentization" in which one part remedy is diluted with 99 parts of water or alcohol, and shaken vigorously. Shaking facilitates to release the remedy's electromagnetic energy. Dilution may be continued in different strengths. The more a medicine is diluted, the more effective and powerful it becomes (2). Homeopathy is geographically widespread (3). From one hand we are aware that many studies have confirmed the positive effects of homeopathic medicines (4-9), on the other hand homeopathic remedies is not inferior to conventional remedies in primary cares (10). Many studies have indicated that the homeopathic treatments lead not only to the usage of minimal drugs dosage, but also shorten the average length of disease in many cases $(4,7,9)$. Homeopathic remedies have no side effects and neither toxic reactions $(7,11)$. Analysis of pooled data approved the significant effects of homeopathic medicines on animals like mice (12). Homeopathy is a perfect complement to the science of midwifery (13). Since much diluted amount of the original substances are used in homeopathic treatments, consequently this alternative medicine doesn't have any side effect; therefore it could be used confidently under supervision of a homeopathic practitioner) during pregnancy (2). Many women's health problems are definitely treatable by homeopathic medicines. Therapeutic effect of homoeopathy are used in treating of many diseases such as hemorrhage, cysts, vaginal secretions, during of labor and delivery disturbances and gives considerable appropriate results compared to placebo (14). There is no evidence to show the trend of homeopathic researches in the subject category of Obstetrics/Gynecology; hence this paper aims to analyze and visualize the scientific activities in the subject areas of Obstetrics/Gynecology during a period of nineteen years. All papers entitled homeopathy indexed in the databases of Science Citation Index Expanded (SCI-E) and Social Science Citation Index (SSCI) during 1993-2012, were extracted and went under analysis. These databases take the highly prestige journals under consideration, that is 
why we chose them to retrieve all raw data in the field.

\section{Material and Methods}

Database of SCI-E and SSCI from Web of Science (WoS) was used to extract for all papers entitled Homeopathy during a period of nineteen years (1993-2012). Web of Science was powered by ISI Web of Knowledge. WoS database is a collection of cross-searchable databases included SCI-E, SSCI, Arts \& Humanities Citation Index (AHCI), Conference Proceedings Citation Index - Science, and Conference Proceedings Citation Index - Social Science \& Humanities. One may search one or more of these databases; select by checking the boxes. It is possible to search for current information as well as to look back about the situation of desired information, by topic, author, etc. WoS is particularly good for citation searching, to discover how many times a particular author or article has been cited and by whom, and to locate later works which cite a specific article. Extraction of data was limited to the title of papers from advance research menu of WoS. Restriction of papers into titles leads to retrieve the most relevant papers in desired subject area (15). Extraction of data led to 1830 papers entitled homeopathy in the form of journal article, letter, editorial material, review, book review, proceeding paper, news item, meeting abstract, correction, biographical item and note.

\section{Results}

Extracting of papers entitled Homeopathy from the database of WoS through 1993-2012 resulted 1830 papers. Analysis of data showed that the number of publication entitled homeopathy indexed in WoS has increased steadily in spite of some fluctuation during the period of study. The number of papers entitled Homeopathy increased from 21 papers in 1993 into 117 papers in 2012, an increase of greater than 5 times. The most prolific year was 2010 with 158 papers ( $8 \%$ ) (Figure 1). Regarding to the countries, England sharing a total number of 368 (20\%) papers in the field was the most productive one followed by USA publishing 319 papers (17\%), and Germany 289 papers $(16 \%)$. It is considerable that Iran sharing eight papers in the field positioned at $24^{\text {th }}$ of rankings table and placed higher than Argentina as well as South Africa. A total number of 560 journals contributed publishing of papers entitled Homeopathy through the time span 19932012. Base on the Brad Ford's scattering law, the Journal of Homeopathy publishing 13\% of global papers in the field, was the most prolific journal among core journals. The followings were Journal of Alternative and Complementary Medicine and Forschende komplementärmedizin (Figure 2 ). About $61 \%$ of papers were distributed in the format of journal articles, $14 \%$ in the form of letters, $9 \%$ in the form of Editorial Materials, $9 \%$ in the form of reviews. Some papers $(7 \%)$ were published in the forms of book review, proceeding paper, news item, meeting abstract, correction, biographical item and note. English was the dominant language of published papers entitled Homeopathy, $87 \%$ of papers was in English. This phenomenon should not come as a surprise; the study of Biglu and Umstätter indicated that the editorial policy of papers has been focused on papers in English language (15).

The University of Exeter in England sharing 69 papers in the field was the most prolific organization producing and publishing papers in the field of homeopathy followed by Switzerland University Bern (44 papers), England University Plymouth (32 papers), England Royal London Homeopath Hospital (28 papers), England University Southampton (27 papers), Germany Tech University Munich (24 papers) and USA University Arizona (23 papers) (Figure 3). The top ten categories of papers consist of Integrative Complementary Medicine, Medicine General Internal, Veterinary Sciences, Pharmacology Pharmacy, Public Environmental Occupational Health, Oncology, Health Care Sciences Services, Pediatrics, Clinical Neurology and Multidisciplinary Sciences. Subject area of Integrative Complementary Medicine was the most frequented subject area of papers entitled homeopathy indexed in WoS during the period of study. A total number of 36 papers were in the subject area of Obstetrics \&. The contain analysis of papers in subject area of Obstetrics \& Gynecology categorized in ten subcategories: Pregnancy and delivery (25\%), Menopausal symptoms (17\%), Homeopathy in gynecology (17\%), Menstrual period disorders (11\%), Reproductive medicine

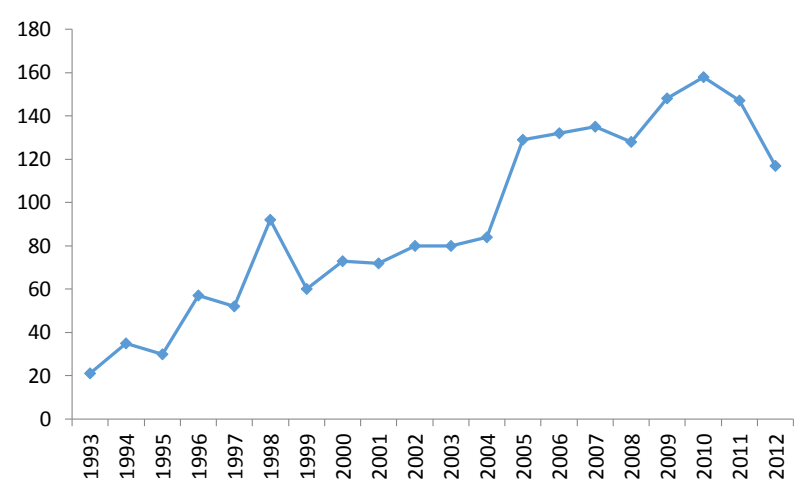

Figure 1. Number of papers entitled Homeopathy indexed in WoS 1993-2012.

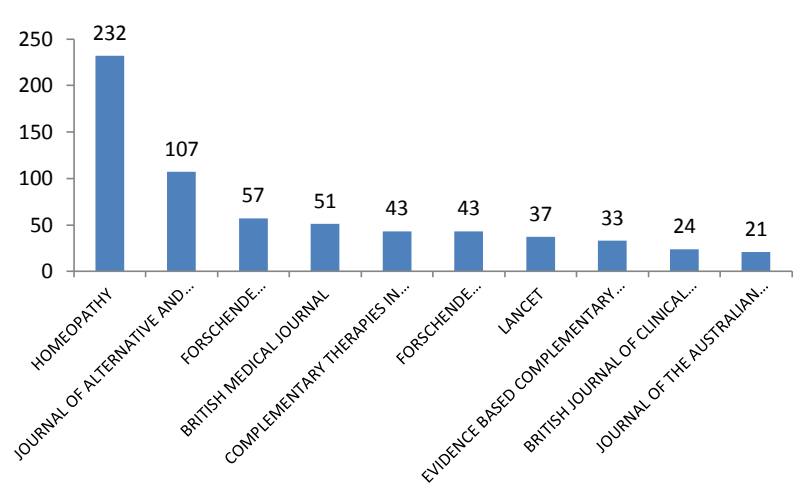

Figure 2. Top prolific Journals publishing papers entitled Homeopathy in WoS 1993-2012. 


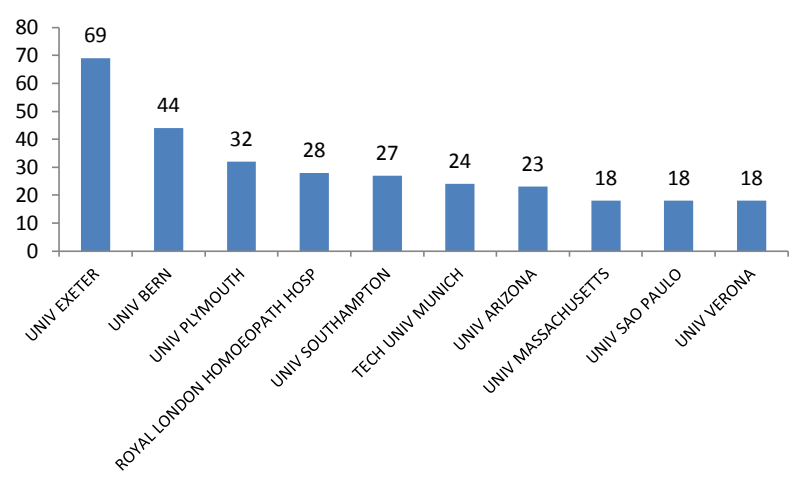

Figure 3. Most prolific institutes sharing papers entitled Homeopathy in WoS 1993-2012

Table 1. Sub-categories of papers in subject area of Obstetrics \& Gynecology indexed in WoS 1993-2012.

\begin{tabular}{llc}
\hline Rank & Sub-categories & Number (\%) \\
\hline 1 & Pregnancy and delivery & $9(25 \%)$ \\
2 & Menopausal symptoms & $6(17 \%)$ \\
3 & Homeopathy in gynecology & $6(17 \%)$ \\
4 & Menstrual period disorders & $4(11 \%)$ \\
5 & Reproductive medicine & $3(8 \%)$ \\
6 & Cancer & $3(8 \%)$ \\
7 & Recurrent vulvovaginal candidiasis & $2(5 \%)$ \\
8 & Lactation & $1(3 \%)$ \\
9 & Myoma & $1(3 \%)$ \\
10 & Recurrent gynecological and urinary & $1(3 \%)$ \\
\hline
\end{tabular}

(8\%), Cancer (8\%), Recurrent vulvovaginal candidiasis (5\%), Lactation (3\%), Myoma (3\%), and Recurrent gynecological and urinary tract infections (13\%) (Table 1).

\section{Conclusion and Discussion}

Analysis of data indicated that a total number of 1830 papers entitled homeopathy indexed in WoS during the period of study. In spite of some fluctuations the number of papers in the field has increased linear, nevertheless the study pointed out that only $2 \%$ of total published papers was in the subject area of Obstetrics \& Gynecology. Regarding to the effective role of homeopathy on Obstetrics \& Gynecology this amount seems to be very redundant and small; therefore the attention of scientists and policy makers of research centers are needed. There is no doubt that many areas of gynecology are often overspecialized, with overuse of surgery that considerable amount of them are unnecessary. Using the contraceptives and fertility pills are dangerous to the patient, especially hormonal treatments which are often carcinogenic and shows side effects. For instance estrogen given for hot flashes and vaginal dryness, causes unwanted fat and water retention, and increase the risk of endometrial cancer and breast cancer. Disease usually originates in the body long before symptoms appear. Homeopathy focuses on understanding initial causes of disease, not waiting to treat later pathology. Homeopathy is an effective and safe alternative to synthetic hormones. It does not place the patient at risk. Based on treating "like with like," homeopathy uses the individualized remedy which produces similar symptoms in a proving testing the remedy's effects on healthy people) and matches this similar remedy to those symptoms the patient is experiencing (16).

Regarding to the prolific countries in the field, England was appeared more active than the USA. The majority of publication in the field came from two developed region Western Europe and North America). This is not the first study that showed the dominance of these regions in scientific activities; previous researches also verified the impact of these region in science $(17,18,19)$. Possibly the reason was that, some leading institutes in Homeopathy such as the University of Exeter, University of Plymouth, Royal Homeopath Hospital of London and University of Southampton are located in England. On the other hand the publishers of $40 \%$ of core journals in the field of Homeopathy are from this country. Contents analysis of papers in the subject area of homeopathy indicated that Pregnancy \& delivery and Menopausal symptoms are the most interesting areas of scientists in the field.

\section{Ethical issues}

The local ethics committee approved the study.

\section{Conflict of interests}

Authors declare that there is no conflict of interests.

\section{Acknowledgments}

We would like to thank all of our colleagues who helped us in this study.

\section{References}

1. Break N. Berek and Novak's gynecology. 14th ed. California: Lippincott Williams \& Wilkins;2007. p. 372-373.

2. Brennan P. Homeopathic remedies for the birth bag. 4 ed. Michigan: Center for the Childbearing;2000. p.1-5.

3. Fisher P. What is homeopathy? An introduction. (Front Biosci Elite Ed) 2012; 4: 1669-82.

4. Sinha MN, Siddiqui VA, Nayak C, Singh V, Dixit R, Dewan D, et al. Randomized controlled pilot study to compare Homeopathy and Conventional therapy in Acute Otitis Media. Homeopathy 2011; 101: 5-12.

5. Rossi E, Bartoli P, Bianchi A, Da Frè M. Homeopathy in paediatric atopic diseases: long-term results in children with atopic dermatitis. Homeopathy 2012; 101: 13-20.

6. Nayak C, Singh V, Singh VP, Oberai P, Roja V, Shitanshu SS, et al. Homeopathy in chronic sinusitis: a prospective multi-centric observational study. Homeopathy 2012; 101: 84-91.

7. Bawden S. Running an NHS community homeopathy clinic - 10-year anniversary 2001-2011. Homeopathy 2012; 101: 51-6. 
8. Brien SB, Leydon GM, Lewith G. Homeopathy enables rheumatoid arthritis patients to cope with their chronic ill health: A qualitative study of patient's perceptions of the homeopathic consultation. Patient Educ Couns 2011; 89: 507-16.

9. Grundling C, Schimetta W, Frass M. Real-life effect of classical homeopathy in the treatment of allergies: A multicenter prospective observational study. Wien Klin Wochenschr 2012; 124: 11-7.

10. Bellavite P, Marzotto M, Chirumbolo S, Conforti A. Advances in homeopathy and immunology: a review of clinical research. Front Biosci (Schol Ed) 2011; 3: 1363-89.

11. Oberbaum M, Samuels N, Ben-Arye E, Amitai Y, Singer SR. Apparent life-threatening events in infants and homeopathy: an alternative explanation. Hum Exp Toxicol 2012; 3: 3-10.

12. Bellavite P, Conforti A, Marzotto M, Magnani P, Cristofoletti M, Olioso D, et al. Testing homeopathy in mouse emotional response models: pooled data analysis of two series of studies. Evid Based Complement Alternat Med 2012;2012:954374.

13. Brennan P. Homeopathic remedies for the birth bag. 4 ed. Michigan: Center for the Childbearing; 2000.

14. Kleijnen J, Knipschild P, Riet G. Clinical trials of homoeopathy. BMJ 1991; 302: 316-23.

15. Biglu $\mathrm{MH}$, Umstätter $\mathrm{W}$. The editorial policy of languages is being changed in Medline. Acimed 2007; 16: 3 .

16. http://homeopathybewell.com/index.htm. Accessed 21 December 2013

17. Biglu $\mathrm{MH}$. Patent literature trends in Medline throughout 1965-2005. ACIMED. 2009; 20:1-8.

18. Biglu MH, Chakhmachi Dovom N, Shahkhodabandeh S. World Scientific Output with Emphasis on Iran in the Field of Psychology in Medline (2000-2010). IJPCP 2013; 192: 97-101.

19. Biglu $\mathrm{MH}$, Biglu $\mathrm{S}$, Saberian-Brojeni $\mathrm{M}$, Shahmohammadi G. Scientific Profiles in the field of Biomarkers (2000-2010). IJISM 2013; 11(2):25-34.

Copyright $\odot 2014$ The Author(s); This is an open-access article distributed under the terms of the Creative Commons Attribution License (http://creativecommons.org/licenses/by/4.0), which permits unrestricted use, distribution, and reproduction in any medium, provided the original work is properly cited. 